\title{
OTIMIZAÇÃO DA DESIDRATAÇÃO OSMÓTICA E SECAGEM DA PIMENTA MALAGUETA (Capsicum frutescens)
}

\author{
Optimization of osmotic dehydration and drying of chilly pepper (Capsicum \\ frutescens)
}

Optimización de la deshidratación osmática y secado del pimiento chile (Capsicum frutescens)

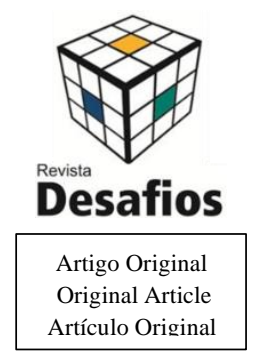

\section{Hermanny Matos Silva Sousa ${ }^{1}$; Cecília Marques Tenório Pereira*22; Denise Gomes Alves ${ }^{3}$; Warley Gramacho da Silva ${ }^{4}$}

${ }^{1}$ Discente do Mestrado em Ciência e Tecnologia de Alimentos, Laboratório de Cinética e Modelagem de Processos, Universidade Federal do Tocantins, Palmas, Brasil.

${ }^{2}$ Bacharel em Nutrição, Universidade Federal do Tocantins, Palmas, Brasil.

${ }^{3}$ Professora, Doutora em Engenharia de Alimentos, Universidade Federal do Tocantins, Palmas, Brasil.

${ }^{4}$ Professor, Doutor em Ciência da Computação, Universidade Federal do Tocantins, Palmas, Brasil.

*Correspondência: Universidade Federal do Tocantins, Av. NS 15, 109 Norte, Palmas, Tocantins, Brasil. CEP:77.010-090.e-mail cecilia.tenorio@mail.uft.edu.br.

Artigo recebido em 23/04/2020 aprovado em 12/05/2020 publicado em 03/07/2020.

\section{RESUMO}

A pimenta malagueta (Capsicum frutescens) é bastante apreciada, não apenas pela sua importância econômica, mas também ao seu rico valor nutricional. Uma alternativa para aumentar a vida útil dos alimentos poderia ser a utilização de métodos de desidratação. A metodologia de superfície de resposta consiste numa ferramenta matemática e estatística que consegue avaliar simultaneamente a influência de diferentes fatores, as estruturas de redes neurais artificiais tem-se a solução de diversos tipos de problemas $\mathrm{O}$ objetivo deste trabalho é Otimização do tratamento osmótico da pimenta malagueta fazendo uso das técnicas de Metodologia de Superfície de Resposta e Redes Neurais Artificiais. No processo de desidratação osmótico o planejamento experimental utilizado foi o fatorial completo $2^{3}$ com 1 ponto central e 6 pontos axiais totalizando 15 experimentos. A secagem convencional foi realizada após a escolha das melhores condições de desidratação osmótica a partir do gráfico de desejabilidade. Utilizando as melhores condições de desidratação osmóticas, as amostras em seguida foram colocadas em estufa nas temperaturas para proceder a análise da cinética de secagem. O processo de desidratação foi eficiente para as variáveis de resposta de PA, GS e IED para as duas soluções desidratantes ainda que não apresentassem efeito significativo.

Palavras-chave: Otimização; desidratação osmótica, rede neural artificial

\section{ABSTRACT}

Chilli pepper (Capsicum frutescens) is highly appreciated, not only for its economic importance, but also for its rich nutritional value. An alternative to increase the shelf life of food could be the use of dehydration methods. The response surface methodology consists of a mathematical and statistical tool that is able to simultaneously evaluate the influence of different factors, the structures of artificial neural networks have the solution of several types of problems. The objective of this work is Optimization of the osmotic treatment of chili peppers making use of Response Surface Methodology techniques and Artificial Neural Networks. In the osmotic dehydration process, the experimental design used was the complete factorial 23 with 1 central point and 6 axial points totaling 15 experiments. Conventional drying was performed after choosing the best osmotic dehydration conditions from the desirability graph. Using the best osmotic dehydration conditions, the samples were then placed in an oven at temperatures to proceed with the analysis of drying kinetics. The dehydration process was efficient for the PA, GS and IED response variables for the two dehydrating solutions even though they did not have a significant effect. 
Keywords: Optimization; osmotic dehydration, artificial neural network

\section{RESUMEN}

La guindilla (Capsicum frutescens) es muy apreciada, no solo por su importancia económica, sino también por su rico valor nutricional. Una alternativa para aumentar la vida útil de los alimentos podría ser el uso de métodos de deshidratación. La metodología de superficie de respuesta consiste en una herramienta matemática y estadística que es capaz de evaluar simultáneamente la influencia de diferentes factores, las estructuras de redes neuronales artificiales tienen la solución de varios tipos de problemas. El objetivo de este trabajo es la optimización del tratamiento osmótico de los chiles utilizando técnicas de Metodología de Superficie de Respuesta y Redes Neuronales Artificiales. En el proceso de deshidratación osmótica, el diseño experimental utilizado fue el factorial completo 23 con 1 punto central y 6 puntos axiales con un total de 15 experimentos. El secado convencional se realizó después de elegir las mejores condiciones de deshidratación osmótica del gráfico de deseabilidad. Utilizando las mejores condiciones de deshidratación osmótica, las muestras se colocaron en un horno a temperaturas para proceder con el análisis de la cinética de secado. El proceso de deshidratación fue eficiente para las variables de respuesta PA, GS e IED para las dos soluciones deshidratantes, aunque no tuvieron un efecto significativo.

Descriptores: Optimización; deshidratación osmótica, red neuronal artificial.

\section{INTRODUÇÃO}

O gênero Capsicum compreende cerca de 60 espécies de pimenta, das quais só cinco espécies foram domesticadas, dentre elas se encontram: Capsicum annuum, $C$. pubescens, $C$. chinense e $C$. baccatum, $C$. frutescens, sendo esta última, a espécie utilizada neste estudo (YANÉZ P, et al., 2015; FINGER e PEREIRA, 2016).

As capsaicinas são responsáveis pelo sabor pungente das pimentas. Eles são restritos ao gênero Capsicum e são sintetizados pela acilação do composto aromático vanillilamina, com um ácido graxo de cadeia ramificada por catálise da enzima putativa capsaicina sintase (CS) (ARCE-RODRÍGUEZ e OCHOA-ALEJO, 2017).

Uma alternativa para aumentar a vida útil dos alimentos poderia ser a utilização de métodos de desidratação, o que proporcionaria a disponibilidade do produto o ano todo ao consumidor. A desidratação de frutas é quando a remoção da água acontece junto com a penetração do soluto. (ANTUNES et al., 2017; BERK, 2018).

Embora os métodos de desidratação e secagem demonstrem inúmeros benefícios, deve-se considerar que os alimentos submetidos a esses tratamentos podem apresentar algumas mudanças indesejáveis ao produto, tais como o aumento da dureza e reidratação lenta ou incompleta no armazenamento (TADINI et al.,2016).

O Gráfico de Pareto é um gráfico de barras que ordena as frequências das ocorrências, da maior para a menor, permitindo a priorização dos problemas. Serve para visualizar e identificar as causas ou problemas mais importantes. O processo final resulta em uma ilustração simples e que facilita a concentração de esforços para a análise de problemas (VIEIRA, 2014).

A Metodologia de Superfície de Resposta (MSR) tem sido uma das ferramentas mais populares de otimização dos últimos anos e sua importância está ligada às suas principais funções: desenvolver, melhorar e otimizar um processo. Compreende aplicações importantes nas etapas de projeto, desenvolvimento e formulação de novos produtos. (MYERS; MONTGOMERY; ANDERSON-COOK, 2016)

Os modelos de Rede Neural Artificiais (RNA's) têm sido constantemente explorados em processamento de imagens e reconhecimento de padrões, pois, uma vez treinada, a ativação de uma rede neural é extremamente rápida, o que a torna atraente para problemas que requerem processamento em tempo real (MORAES, 2010). 
O objetivo deste trabalho é Otimização do tratamento osmótico da pimenta $C$. frutescens fazendo uso das técnicas de MSR e RNA, bem como o tratamento secundário para obtenção de pimenta desidratada.

\section{MATERIAL E MÉTODOS}

\section{Material}

A pimenta malagueta (C. frutescens), e o açúcar refinado, juntamente com a canela em pau, foram adquiridos em uma rede de supermercados do município de Palmas - TO.

\section{Planejamento Experimental}

No processo de desidratação osmótico o planejamento experimental utilizado foi $\mathrm{o}$ fatorial completo $2^{3}$ com 1 ponto central e 6 pontos axiais totalizando 15 experimentos.

\section{Desidratação Osmótica}

A solução osmótica foi preparada utilizando-se açúcar refinado comercial e água destilada, de acordo com Andrade et al. (2007). As concentrações das soluções foram definidas de acordo com o delineamento experimental (Tabela 1).

A pimenta, foi selecionada e separada do cabo, lavada em água corrente e higienizada em solução de hipoclorito de sódio a 200 ppm por 20 minutos e pesouse aproximadamente 10 gramas de pimenta para cada $100 \mathrm{ml}$ das soluções desidratantes

Foram preparadas soluções desidratantes utilizando 5 concentrações diferentes de açúcar (Tabela 1), sendo estas: 23, 30, 40, 50 e 57 gramas (p/v).

Tabela 1 - Delineamento Experimental com três variáveis independentes: X1 (temperatura); X2 (concentração da solução osmótica); e X3 (tempo).

\begin{tabular}{ccccccc}
\hline \multirow{2}{*}{ Ensaio $\left(\mathrm{n}^{\circ}\right)$} & \multicolumn{2}{c}{ Variáveis Codificadas } & \multicolumn{2}{c}{ Variáveis Reais } \\
\cline { 2 - 7 } & $\mathrm{X}_{1}$ & $\mathrm{X}_{2}$ & $\mathrm{X}_{3}$ & Temperatura $\left({ }^{\circ} \mathrm{C}\right)$ & Concentração da solução osmótica & Tempo (horas) \\
\hline 1 & -1 & -1 & -1 & 30 & 30 & 120 \\
2 & -1 & -1 & 1 & 30 & 30 & 240 \\
3 & -1 & 1 & -1 & 30 & 50 & 120 \\
4 & -1 & 1 & 1 & 30 & 50 & 240 \\
5 & 1 & -1 & -1 & 50 & 30 & 120 \\
6 & 1 & -1 & 1 & 50 & 30 & 120 \\
7 & 1 & 1 & -1 & 50 & 50 & 240 \\
8 & 1 & 1 & 1 & 50 & 50 & 180 \\
9 & $-1,68$ & 0 & 0 & 23 & 40 & 180 \\
10 & 1,68 & 0 & 0 & 57 & 40 & 180 \\
11 & 0 & $-1,68$ & 0 & 40 & 23 & 790 \\
12 & 0 & 1,68 & 0 & 40 & 57 & 281 \\
13 & 0 & 0 & -1.68 & 40 & 40 & 180 \\
14 & 0 & 0 & 1,68 & 40 & 40 & 40 \\
$15(\mathrm{C})$ & 0 & 0 & 0 & 40 & &
\end{tabular}

Para a utilização da concentração com chá de canela, utilizou-se 3 palitos de canela de aproximadamente $5 \mathrm{~cm}$ de comprimento para um litro de água destilada. O recipiente foi colocado em uma chapa de aquecimento para procedimento de cocção. Após o líquido levantar fervura, deixou-se assim por 5 minutos e a chapa foi desligada. Por fim, deixou-se o líquido esfriar até atingir temperatura ambiente.

Depois de preparadas as soluções desidratantes as pimentas pesadas foram adicionadas nas soluções 
dentro de Erlenmeyers, cobertos com parafilme. Após isso as amostras foram colocadas no shaker por 30 minutos sem agitação para a pimenta entrar em equilíbrio com a solução desidratante. Passados os 30min ligou-se a agitação constante de 120rpm do Shaker.

Após as amostras serem retiradas do shaker, descartou-se a solução aquosa e as pimentas foram secas com papel absorvente, pesadas em uma balança analítica

Em seguida, foram pesadas $3 \mathrm{~g}$ de cada amostra em um cadinho de alumínio e levadas a estufa a $70^{\circ} \mathrm{C}$ até peso constante para obter suas massas e determinar os percentuais de perda de água (PA), ganho de sólidos (GS) e índice de eficiência da desidratação (IED) da pimenta $C$. frutescens.

As amostras foram analisadas com variação de concentração e tempo, à uma agitação constante de 120rpm, de acordo com a tabela (Tabela 1). Todas as amostras foram realizadas em triplicata.

No presente trabalho, para cada amostra do delineamento experimental, foi realizando seu controle nas mesmas condições, porém com água destilada no lugar do chá de canela.

Os valores obtidos nas determinações analíticas durante a desidratação osmótica foram utilizados para calcular os percentuais de perda de água (PA), ganho de sólidos (GS) do fruto e índice de eficiência da desidratação (IED), conforme as equações citadas por Raji et. al. (2010) através das equações a seguir:

$$
\begin{aligned}
& \% \mathrm{PA}=\frac{\left(\mathrm{M}_{0}-\mathrm{M}_{\mathrm{t}}\right)+\left(\mathrm{S}_{\mathrm{t}}-\mathrm{S}_{0}\right)}{\mathrm{M}_{0}} \times 100 . \\
& \% \mathrm{GS}=\frac{\mathrm{S}_{\mathrm{t}}-\mathrm{S}_{0}}{\mathrm{M}_{0}} \times 100 \ldots \ldots \ldots \ldots \ldots \ldots \ldots \ldots \ldots \ldots \ldots \ldots \ldots
\end{aligned}
$$

Onde:

$\mathrm{M}_{0}$ - massa inicial da amostra em gramas

$\mathrm{M}_{\mathrm{t}}$ - massa da amostra no tempo $\mathrm{t}$ em gramas

$\mathrm{S}_{0}-$ sólidos iniciais da amostra em gramas
$\mathrm{S}_{\mathrm{t}}$ - sólidos da amostra no tempo $\mathrm{t}$ em gramas.

Para determinação da umidade das amostras foi utilizado o método descrito pelo Instituto Adolfo Lutz (2008).

\section{Secagem Convencional}

A secagem convencional foi realizada após a escolha das melhores condições de desidratação osmótica a partir do gráfico de desejabilidade. Utilizando as melhores condições de desidratação osmóticas, as amostras em seguida foram colocadas em estufa nas temperaturas de $45,50,55,60$ e $65^{\circ} \mathrm{C}$ para proceder a análise da cinética de secagem.

O perfil de desejabilidade é uma ferramenta do software Statistica 7.0, utiliza a abordagem usada por Derringer e Suich (1980), que apresenta a condição que melhor se adapta aos dados. No final do gráfico se apresentam as condições ideais das variáveis de entrada e do lado direito, as variáveis de resposta.

\section{Metodologia de Superfície de Resposta (MSR)}

A MSR consiste numa ferramenta matemática e estatística que consegue avaliar simultaneamente a influência de diferentes fatores, e otimizar suas condições experimentais (CHEN; ZHAO; YU, 2015). A metodologia de superfícies de resposta tem duas etapas distintas (modelagem e deslocamento), que são repetidas tantas vezes quantas forem necessárias, com o intuito de atingir uma região ótima da superfície investigada. A modelagem normalmente é feita ajustando-se modelos simples à resposta obtida com planejamentos fatoriais ou planejamentos fatoriais ampliados. O deslocamento se dá sempre ao longo do caminho de máxima inclinação de um determinado modelo, que é a trajetória na qual a resposta varia de forma mais pronunciada.

A análise estatística foi realizada utilizando o software Statistic (versão 7.0). 


\section{Redes Neurais Artificiais (RNA's)}

A RNA's pode ser usada como uma alternativa à ferramenta de modelagem baseada em regressão polinomial, que fornece a modelagem de relacionamentos não lineares complexos. $\mathrm{O}$ modelo da RNA é potencialmente mais preciso, incluindo todos os dados experimentais (LERTWORASIRIKUL, 2008). A RNA foi desenvolvida usando as condições operacionais do processo de desidratação osmótica para estimar a perda de água, o ganho de sólidos e a relação entre perda de água/ganho de sólidos. A RNA proposta consiste de (1) uma camada de entrada que representam as variáveis de entrada para o problema, (2) uma camada de saída com neurônios que representa a variável dependentes e (3) uma ou mais camadas escondidas contendo neurônios. A figura 1 representa a modelagem do problema através de uma RNA.

Figura 1. Esquema de redes neurais artificiais para o processo de desidratação osmótica

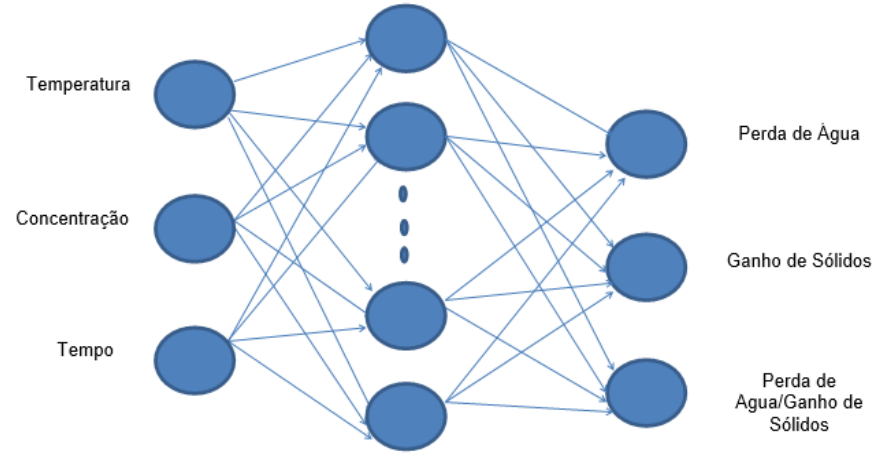

\section{RESULTADOS E DISCUSSÃO}

Os resultados do processo de desidratação osmótica das amostras são apresentados a seguir.

Figura 2. Diagrama de Pareto da Perda de Água com solução desidratante com chá de canela (a) solução desidratante sem chá de canela (b).

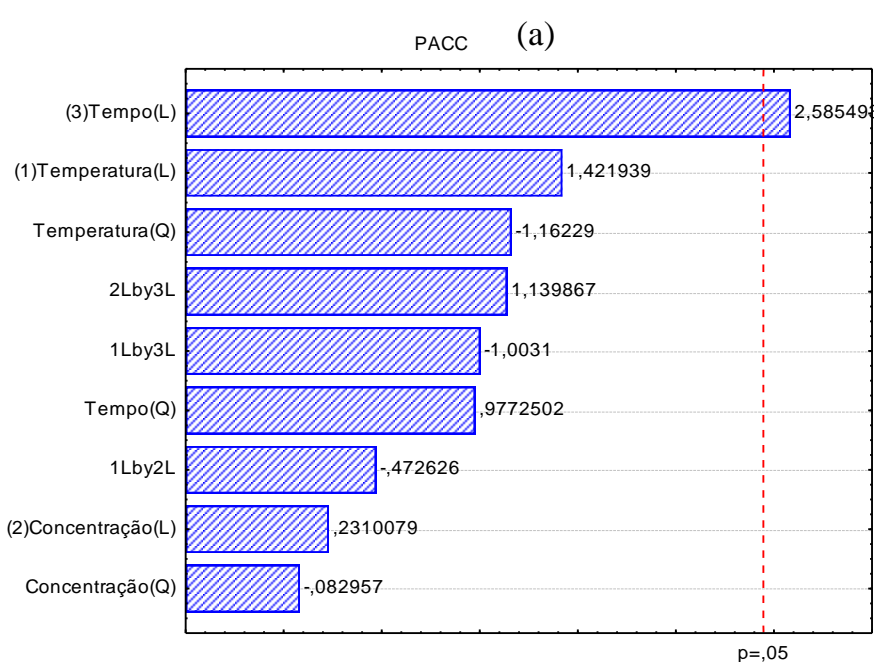

Observou-se que para a solução desidratante utilizando o chá de canela (Figura 2a) a variável que teve maior influência na perda de água foi o tempo e que as outras não apresentaram nenhuma influência nessa resposta. Na solução desidratante sem o chá (Figura $2 b$ ) não houve nenhuma variável que influenciou a resposta, entretanto, a variável de temperatura apresentou maior valor. Contudo apresenta um valor negativo o que indica

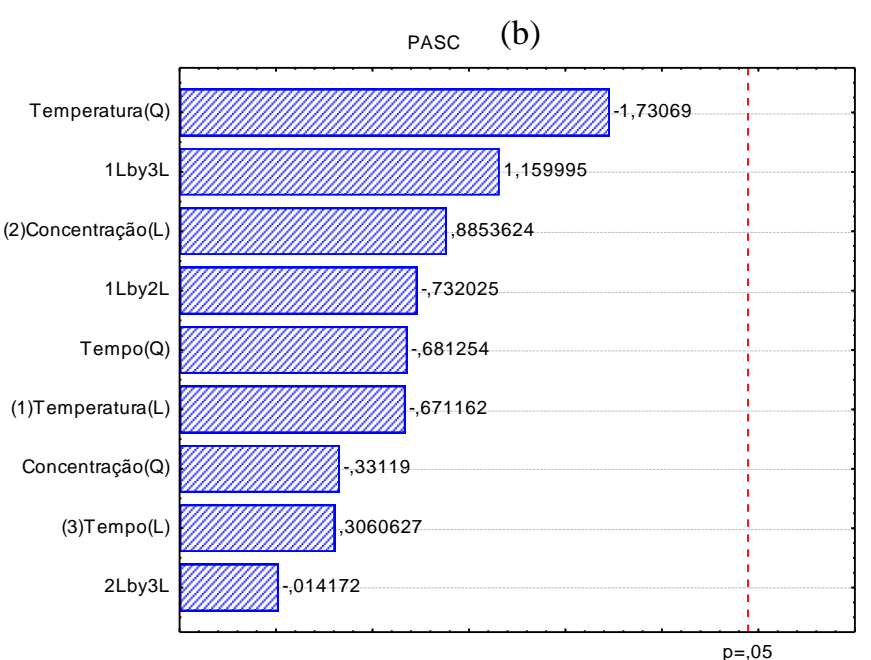

que o aumento da temperatura exerceu efeito contrário sobre a resposta, ou seja, quanto maior a temperatura menor a perda de água.

No trabalho de Alves (2019), podemos constatar uma diferença estre os resultados obtidos. Tanto as soluções com chá de canela, como as sem chá de canela não possuem variáveis que influenciem no valor da perda de água. 
Já no trabalho de Catelan (2014), há um aumento na taxa de secagem, com o aumento de temperatura, e embora exista água superficial livre, ela encontra-se em suspensão com outros constituintes do produto. Suas curvas de taxa de secagem de pimenta malagueta $(C$. frutescens), foram de 50 a $110^{\circ} \mathrm{C}$, sendo a taxa de maior temperatura a de $70^{\circ} \mathrm{C}$, seguindo pela de 60,50 e $40^{\circ} \mathrm{C}$, logo, tem-se que a elevação da temperatura resultou num efeito positivo sobre a taxa de secagem.

Figura 3. Diagrama de Pareto para o Ganho de Sólidos com solução desidratante de chá de canela (a) solução desidratante sem chá de canela (b).

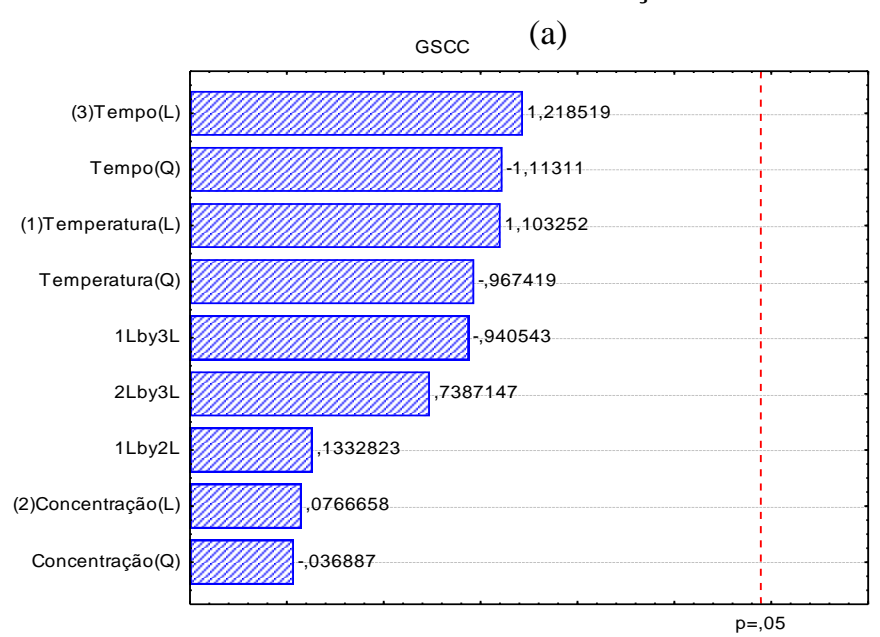

Na resposta do ganho de sólidos observou-se que nenhuma das variáveis das duas soluções desidratantes exerceu influência sobre a resposta, mas para a solução com chá de canela (Figura 3a) o tempo foi a variável de maior valor e na solução sem chá (Figura 3b) a concentração apresenta maior valor.

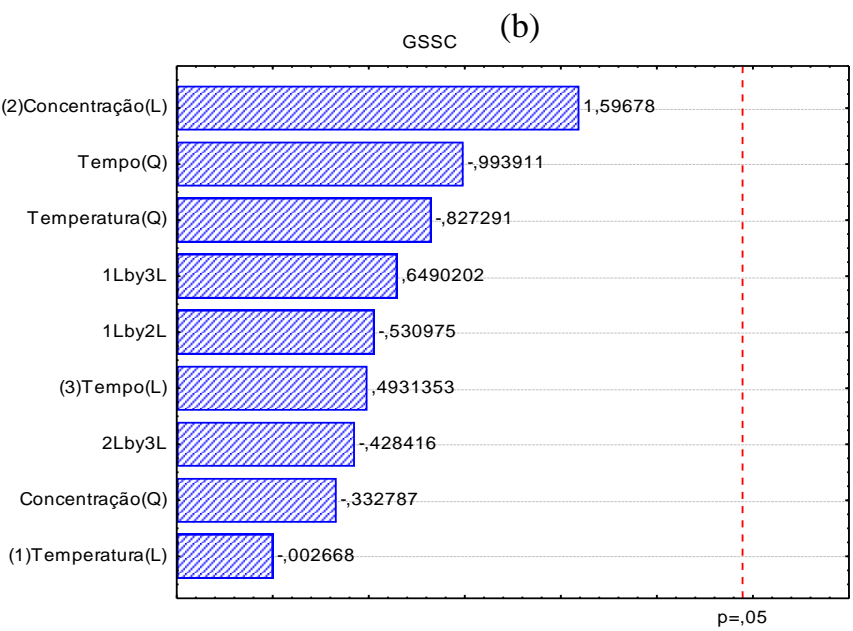

Assim como no trabalho de Alves (2019), nenhuma das variáveis exerceram influência sobre a resposta. Mesmo o trabalho não tendo a variância de "temperatura" como um fator, podemos observar que as demais se encontram bastante similares em seus resultados.

Figura 4. Diagrama de Pareto do Índice de Eficiência da Desidratação com solução desidratante utilizando chá de canela (a) e com solução desidratante sem chá de canela (b).
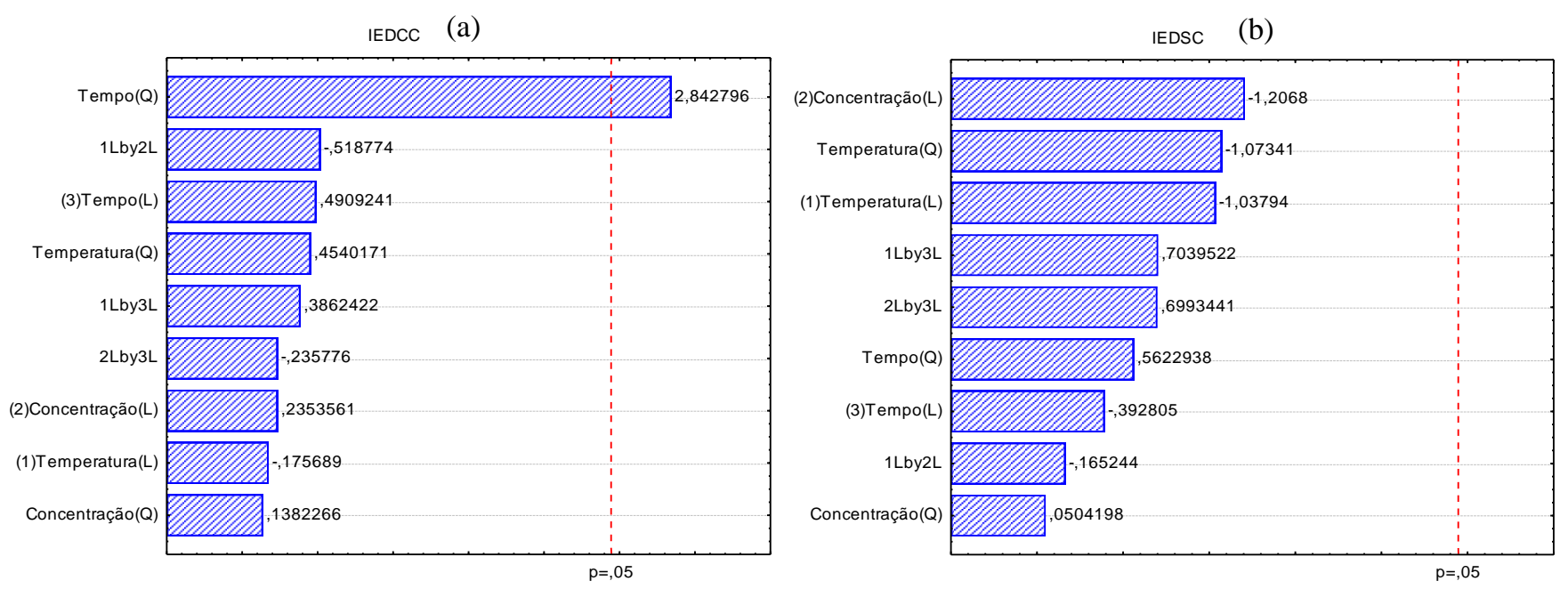
O IED é um adimensional que mostra a tendência das variáveis de resposta de maior perda de água ou de ganho de sólidos. Valores positivos do índice indicam maior perda de água com menor ganho de sólidos, enquanto valores negativos do índice indicam maior ganho de sólidos com menor perda de água. $\mathrm{Na}$ Figura 4 pode-se observar que apenas uma variável em cada solução influenciou a resposta significativamente, enquanto que as outras variáveis não apresentaram efeito significativo na resposta. A Figura 4 a mostrou que o tempo influenciou a variável de resposta significativamente, enquanto a Figura $4 \mathrm{~b}$ apresentou a concentração como a variável de maior influência apresentando efeito negativo, indicando que houve um maior ganho de sólidos com menor perda de água.

Figura 5. Perfil de valores preditos de desejabilidade.

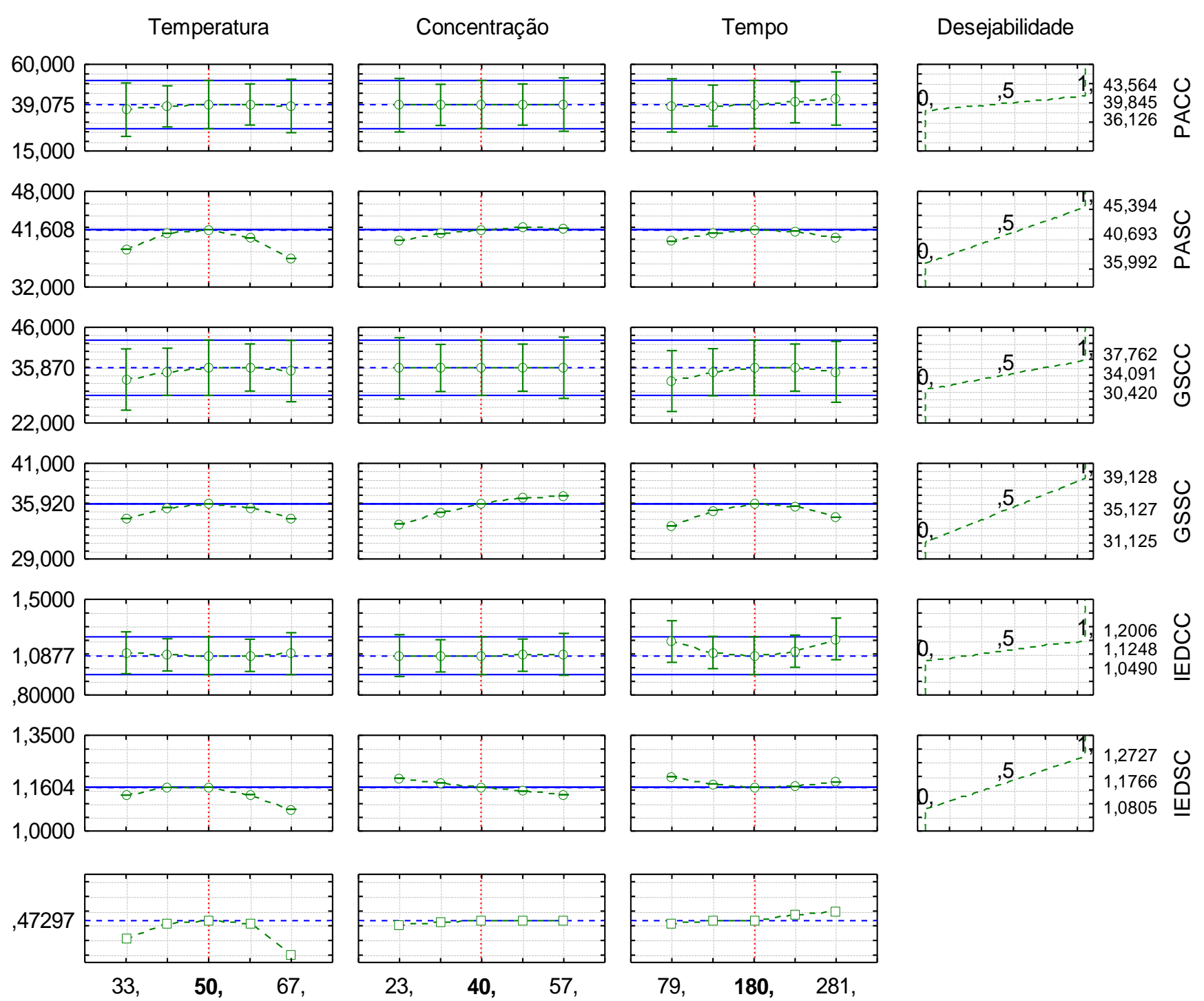

Pode-se observar pela Figura 5 que nas variáveis utilizados na literatura em outros trabalhos de otimização de desidratação osmótica, como trabalho de Derossi et al., (2015) e Szparaga et al., (2019) onde utilizaram

de entrada a melhor condição é a do ponto central que tem temperatura de $50^{\circ} \mathrm{C}, 40 \%$ de concentração da solução e tempo de 180 minutos. Valores similares temperatura de $50^{\circ} \mathrm{C}$ e $20^{\circ} \mathrm{C}$, concentração osmótica de 
$51 \%$ e $35-65 \%$ e tempo de 90 a $180 \mathrm{~min}$ respectivamente. Esses valores podem ser explicados devido fato se altas temperaturas podem sacarificar os carboidratos presentes nas amostras e resultando dados incoerentes, já nas concentrações osmóticas abaixo de $35 \%$ e acima de $65 \%$ são muito lentas, devido à baixa condição para a transferência de massa ou por possui alta viscosidade, o que diminui a absorção do agente osmótico (SZPARAGA et al., 2019).

Para as variáveis de resposta (lado direito do gráfico) observou-se que as soluções desidratantes com uso de chá de canela (PACC, GSCC e IEDCC) apresentam duas linhas contínuas em azul com uma linha tracejada no centro, indicando os limites (inferior e superior) e ponto central, enquanto que nas soluções sem chá de canela (PASC, GSSC e IEDSC) essas linhas coincidem. Nas soluções com chá as linhas contínuas juntamente com a linha tracejada apresentam uma região de solução para a resposta, indicando que dentro dessa faixa as variáveis de resposta podem assumir valores entre os limites e ainda assim obterem bons resultados para o processo, enquanto que nas soluções sem chá onde apenas uma linha é apresentada as variáveis de resposta só apresentam uma condição para cada uma das variáveis.

De acordo com os resultados do processo da desidratação osmótica obtida, foi utilizado os resultados das melhores condições para desidratação osmótica na temperatura de $50^{\circ} \mathrm{C}, 40 \%$ de concentração da solução e tempo de 180 minutos, repetindo as análises nessas mesmas condições, para determinar qual a influência do chá de canela no processo, comparando as metodologias utilizadas: RNA e MSR.

Figura 6 - Gráfico da Perda de Água solução desidratante com chá de canela (a) solução desidratante sem chá de canela (b).

PACC (a)

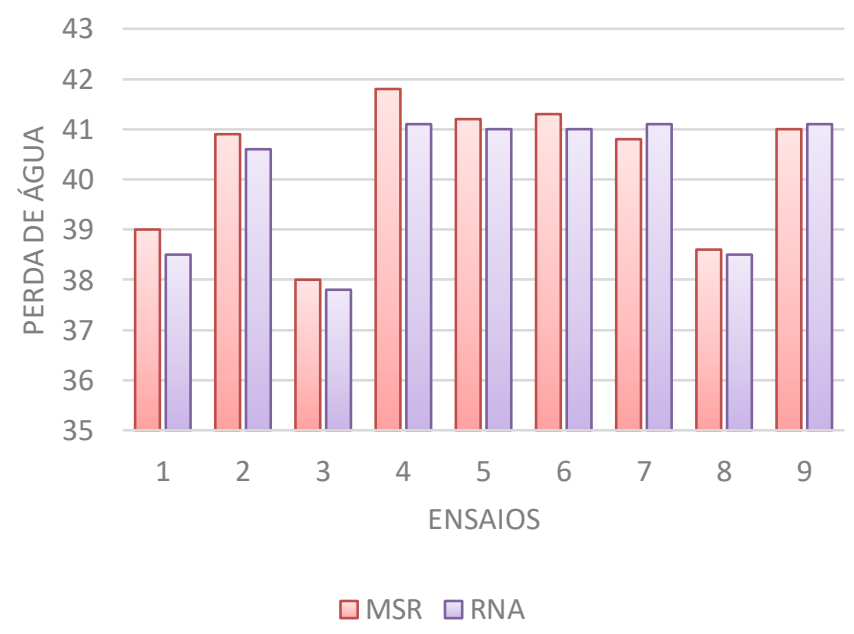

Observou-se na figura 6a, que a perda de água analisada pela MSR se difere em relação a RNA, sendo maior nos ensaios de 4 a 7 . Entretanto, o coeficiente de regressão $\left(\mathrm{R}^{2}\right)$ do RNA se encontra próximo da idealidade, já que obteve o valor de 0,943 , sendo superior
PASC (b)

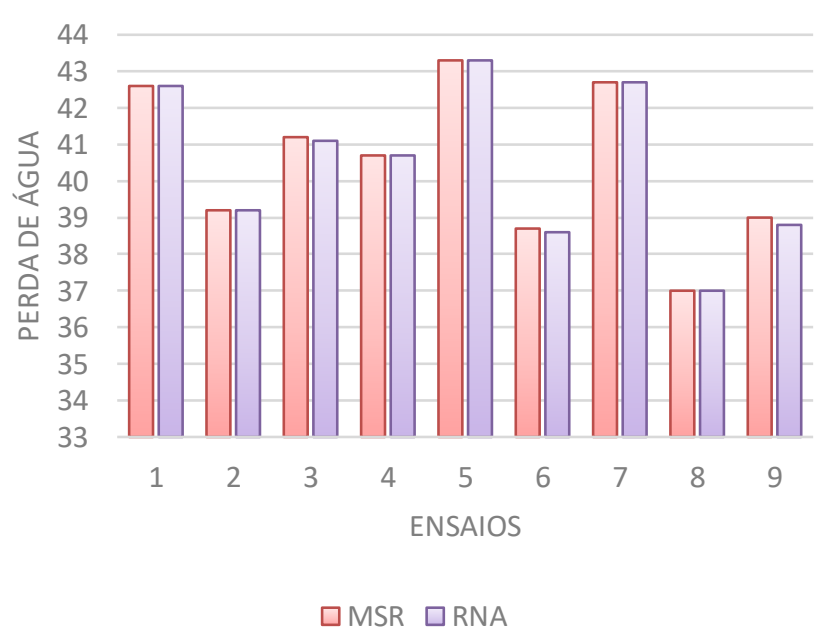

o valor do $\mathrm{R}^{2}$ da MSR, que foi de 0,718 , não obtendo uma linearidade. Na figura $6 \mathrm{~b}$, nota-se apenas uma pequena diferença na perda de água entre as metodologias, contudo, há uma grande diferença entre os $\mathrm{R}^{2}$, onde MSR apresentou 0,516 e RNA 0,997. 
Figura 7. Gráfico para o Ganho de Sólidos com solução desidratante de chá de canela (a) solução desidratante sem chá de canela (b).

GSCC (a)

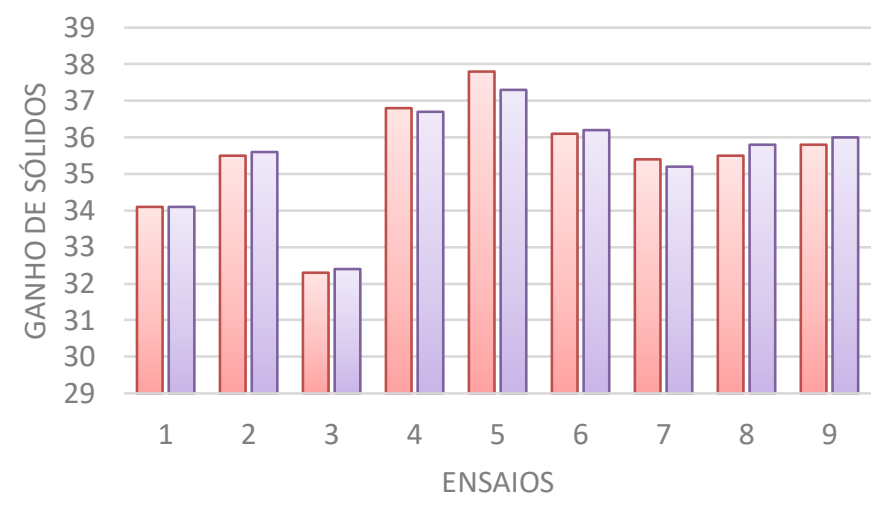

$\square$ MSR $\square$ RNA

Observou-se que na figura 7b, o RNA obteve um ganho de sólidos maior que o MSR, sendo seu $\mathrm{R}^{2}$ superior também. Apresenta valor de 0,986 de $\mathrm{R}^{2}$ para RNA e 0,506 para MSR. Na figura 7b, mostra o equilíbrio entre as metodologias, contudo, a partir do ensaio 8 a RNA contém um ganho de sólidos superior ao da MSR, valor $\mathrm{R}^{2}$ superior também para RNA, apresentando 0,95 e 0,450 para MSR.

Quando a PA e o GS ocorrem em modo paralelo, a taxa de perda de água é sempre maior que o ganho sólido. Aumento do ganho sólido, diminuindo as taxas de perda de água e consequentemente a redução de peso também. O aumento da concentração e agitação leva a mais perda de água do que o ganho sólido, o que causa um aumento na redução de peso. Esse fenômeno é atribuído às diferenças de difusão entre a água e os solutos, relacionadas às suas massas molares (MARAN et al., 2013).

Devido ao processo de aprendizagem das RNA, os resultados mostraram que o $\mathrm{R}^{2}$ médio para PA e GS tendia a aumentar devido as variáveis de entrada e as variáveis respostas. Tais resultados vão de acordo com os resultados obtidos por outros trabalhos (OCHOA-
GSSC (b)

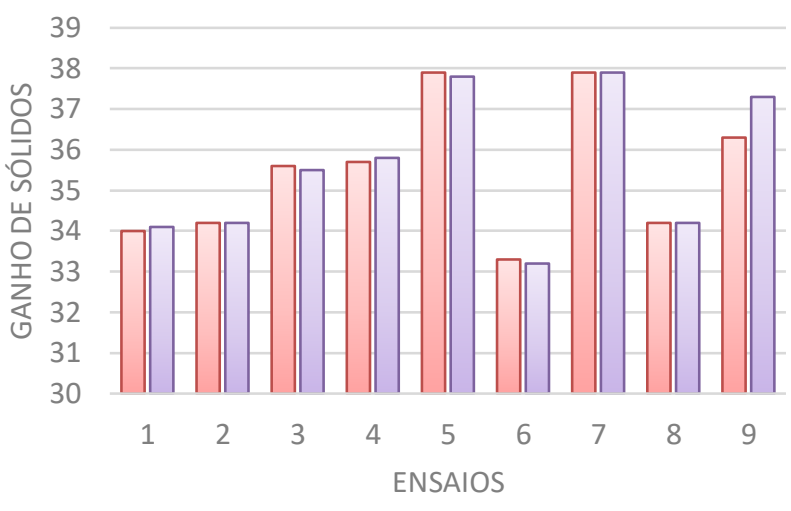

$\square M S R \quad \square R N A$

MARTÍNEZ e AYALA-APONTE, 2007; LERTWORASIRIKUL, 2008; SINGH et al., 2009; LERTWORASIRIKUL e SAETAN, 2010), onde também relataram sobre o desempenho de RNA devido ao número de variáveis envolvidas no estudo. De tal forma, indicando que o modelo RNA possui maior capacidade de modelagem do que os modelos MSR para desidratação osmótica da pimenta malagueta, devido ao modelo de RNA mostrar uma capacidade de generalização significativamente maior que os modelos MSR. Essa maior precisão preditiva da RNA pode ser atribuída à sua capacidade universal de aproximar a não linearidade do sistema, enquanto o MSR é restrito a um polinômio de segunda ordem.

Os efeitos dos parâmetros do processo no teor médio de umidade da pimenta malagueta desidratado osmoticamente em duas soluções osmóticas (com chá e sem chá) estão apresentados na figura 8. Foi possível verificar que as duas soluções obtiveram comportamentos similares, indicando que a solução de chá não obteve influência significativa para o processo de secagem da amostra. 
Figura 8. Gráfico de Umidade com solução desidratante utilizando chá de canela (a) e com solução desidratante sem chá de canela (b).

\section{Umidade com Chá}

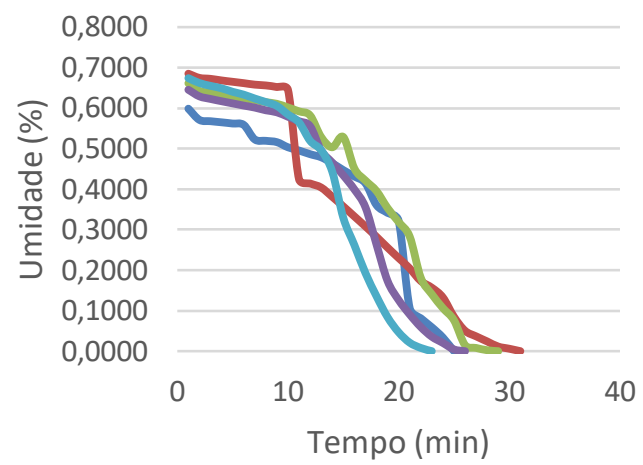

No decorrer da secagem observou-se que as temperaturas elevadas apresentaram menor tempo de secagem, provavelmente devido a alterações nas propriedades físicas das amostras. Temperaturas mais altas causam o aumento da permeabilidade da membrana, o que promove o inchaço e a plastificação das membranas celulares, reduzindo a resistência externa à transferência de massa e facilitando o transporte de água e soluto. Esses resultados foram concordantes com trabalhos anteriores de Sharif et al., (2018); Szparaga et al., (2019) e Sakooei-Vayghan et al., (2020).
Umidade sem Chá (b)

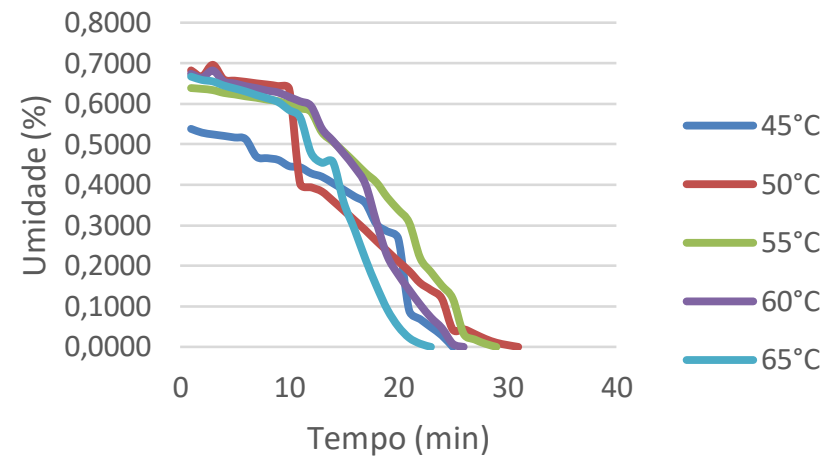

Contudo a temperatura de $45^{\circ} \mathrm{C}$ atingiu a umidade de equilíbrio após 840 minutos o que não é comum por ser uma temperatura baixa, tendo em vista que temperaturas superiores como de $50^{\circ} \mathrm{C}$ e $55^{\circ} \mathrm{C}$ só entraram em equilíbrio após 1200 e 960 minutos respectivamente. Esse comportamento pode ser explicado se no dia do processo de secagem a umidade relativa estiver mais baixa já que esse fator influencia a perda de umidade para o ambiente.

Figura 9. Gráfico do Adimensional com solução desidratante utilizando chá de canela (a) e com solução desidratante sem chá de canela (b).

AD. com Chá (a)

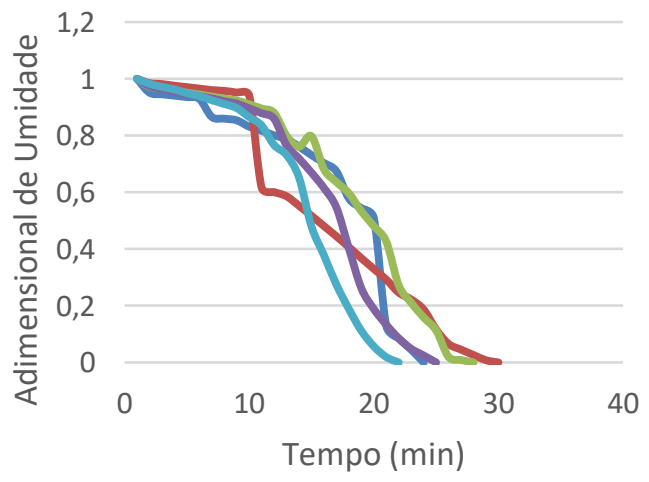

Em materiais biológicos, o período de taxa decrescente de secagem é apresentado utilizando o
AD. sem Chá

(b)

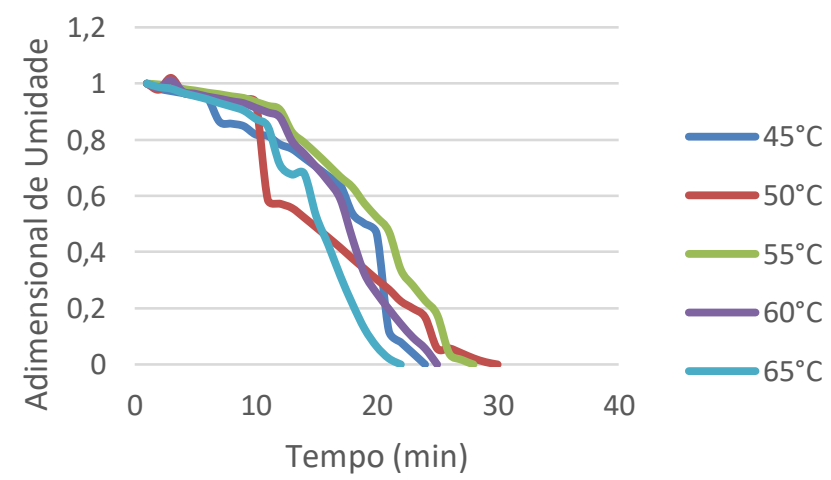

adimensional de umidade., sendo este período caracterizado por uma fase inicial, onde o coeficiente de 
difusão é constante e outra fase final, onde esse coeficiente é reduzido.

$\mathrm{Na}$ figura 9 é apresentado o adimensional calculado, utilizando valores de umidade e observou-se que a solução desidratante feita com chá de canela não influenciou a cinética de secagem das amostras, indicando que a utilização de qualquer uma das soluções desidratantes pode ser eficiente na diminuição do tempo de secagem.

Segundo o trabalho de Alves (2015), observamos que, com o aumento da temperatura, o tempo de secagem para obter o adimensional de umidade igual a 0 foi maior para a temperatura $50^{\circ} \mathrm{C}$; de forma intermediária para a secagem a temperatura $60^{\circ} \mathrm{C}$; e a secagem para temperatura $70^{\circ} \mathrm{C}$ a mais rápida.

\section{CONCLUSÃO}

Mesmo não apresentando efeito significativo nas análises, o processo de desidratação osmótica apresentou resultados eficientes em todas as variáveis de resposta de PA, GS e IED, nas duas soluções desidratantes, com chá e sem chá de canela. A cinética de secagem não apresentou diferenças na perda de umidade nas amostras desidratadas osmoticamente com chá ou sem chá.

Para as análises de RNA e MSR, utilizou-se a melhor condição do processo, sendo esta do ponto central, com temperatura de $50^{\circ} \mathrm{C}$, concentração da solução de sacarose de $40 \%$ e o tempo de 180 minutos.

Entre os processos de otimização osmótica de MSR e RNA, a utilização de RNA foi a mais eficiente. A RNA apresentou melhores valores de $\mathrm{R}^{2}$ do que a MSR, apresentando, consequentemente, um melhor ajuste aos dados experimentais de PA e GS.

Podemos perceber a variável temperatura foi a que mais teve efeito no processo de secagem e desidratação da pimenta.
Todos os autores declararam não haver qualquer potencial conflito de interesses referente a este artigo.

\section{REFERENCIAS}

ALVES, D. A. S. Secagem de pimenta-do-reino preta (Piper nigrum L.) em secador de leito fixo. Dissertação (Mestrado em Engenharia Química) - Universidade Federal de São Carlos, São Carlos, 2015.

ALVES, D. G.; ABREU, C. N.; SOUSA, H. M. S.; PEREIRA, C. M. T. Avaliação do Processo de Desidratação Osmótica de Pimenta Malagueta (Capsicum frutens), variedade Malaguetinha. Revista Desafios, v6 - Especial, p 60-64, 2019

ANDRADE, S. A. C.; NETO, B. B.; NÓBREGA, A. C.; AZOUBEL, P. M.; GUERRA, N. B. Evaluation of water and sucrose diffusion coefficients during osmotic dehydration of jenipapo (Genipa Americana L.). Journal of Food Engineering, v. 78, n. 2, p. 551-555, 2007

ANTUNES, B. F.; JACQUES A. C.; OLIVEIRA, F. M.; OLIVEIRA, R. M.; MANERA, A. P. Estabilidade de morango (Fragaria l.) Liofilizado e armazenado a vácuo. Revistada Jornada da Pósgraduação e Pesquisacongrega Urcamp, Si, v. 1, n. 1, p.1-14, jan. 2017.

ARCE-RODRÍGUEZ, M.L.; OCHOA-ALEJO, N. 2017. An R2R3-MYB Transcription factor regulates capsaicinoid biosynthesis. Plant Physiology. 174:13591370 .

BERK, Z. Food process engineering and technology. Academic Press, 2018.

CATELAN, K. T.; NAKAMURA, M. M. N.; TELISROMETO, J. Cinética de secagem e coeficiente de difusividade de pimentas malaguetas desidratadas em secador de leito fixo. XX Congresso Brasileiro de Engenharia Química, Florianópolis, SC. 2014.

CHEN, M.; ZHAO, Y.; YU, S. Optimisation of ultrasonic-assisted extraction of phenolic compounds, antioxidants, and anthocyanins from sugar beet molasses. Food Chemistry, v. 172, p. 543-550, 2015.

DEROSSI, A., SEVERINI, C., DEL MASTRO, A., \& DE PILLI, T. (2015). Study and optimization of osmotic dehydration of cherry tomatoes in complex solution by response surface methodology and desirability approach. LWT-Food Science and Technology, 60(2), 641-648. 
DERRINGER, G.; SUICH, R. Relationships derived from physical properties of vegetable oil and biodiesel fuels FUEL. V87 n22 p 214-219, 1980

DUTRA, F. J. A; MELO, L. J. O. T.; RESENDE, L. V.; ANUNCIAÇÃO, F. C. J.; BASTOS, G. Q.A, F. J. A. Aplicação de técnicas multivariadas no estudo da divergência genética em cana-de-açúcar. Revista Ciência Agronômica, v. 42, n. 1, p. 185-192. 2010.

INSTITUTO ADOLFO LUTZ. Métodos físio-químicos para análise de alimentos. Coordenadores Odair Zenebon, NeusSadoccoPascuet e Paulo Tiglea - São Paulo: Instituto Adolfo Lutz, p. 1020, 2008.

LERTWORASIRIKUL, S. Drying kinetics of semifinished cassava crackers: A comparative study. LWTFood Science and Technology, v. 41, n. 8, p. 13601371, 2008.

LERTWORASIRIKUL, S.; SAETAN, S. Artificial neural network modeling of mass transfer during osmotic dehydration of kaffir lime peel. Journal of Food Engineering, v. 98, n. 2, p. 214-223, 2010.

MARAN, J. P., SIVAKUMAR, V., THIRUGNANASAMBANDHAM, K., \& SRIDHAR, R. (2013). Artificial neural network and response surface methodology modeling in mass transfer parameters predictions during osmotic dehydration of Carica papaya L. Alexandria Engineering Journal, 52(3), 507-516.

MORAES, E. C. Reconhecimento de Padrões e Redes Neurais Artificiais em predição de estruturas secundárias de proteínas. Tese (Doutorado) COPPE/UFRJ, 2010.

MYERS, R. H.; MONTGOMERY, D. C.; ANDERSONCOOK, C. M. Response surface methodology: process and product optimization using designed experiments. John Wiley \& Sons, ed. 4, 855 p., 2016.

OCHOA-MARTÍNEZ, C. I.; AYALA-APONTE, A. A. Prediction of mass transfer kinetics during osmotic dehydration of apples using neural networks. LWTFood Science and Technology, v. 40, n. 4, p. 638-645, 2007.

PINTO, C. M. F.; PINTO, C. L. O.; DONZELES, S. M. L. Pimenta Capsicum: propriedades químicas, nutricionais, farmacológicas e medicinais e seu potencial para o agronegócio. Revista Brasileira de Agropecuária Sustentável, v. 3, p. 108-120, 2013. H
RAJI, A.; FALADE K. O.; BIMBOLU, F. Effect of sucrose and binary solution on osmotic dehydration of pepper varieties (Capsicum spp.) J Food Sci Technol. 2010;47(3):305-309. doi: 10.1007/s13197-010-0048- 7.

SAKOOEI-VAYGHAN, R., PEIGHAMBARDOUST, S. H., HESARI, J., \& PERESSINI, D. (2020). Effects of osmotic dehydration (with and without sonication) and pectin-based coating pretreatments on functional properties and color of hot-air dried apricot cubes. Food Chemistry, 311, 125978.

SHARIF, I., ADEWALE, P., DALLI, S. S., \& RAKSHIT, S. (2018). Microwave pretreatment and optimization of osmotic dehydration of wild blueberries using response surface methodology. Food chemistry, 269, 300-310.

SINGH, R. R. B., RUHIL, A. P., JAIN, D. K., PATEL, A. A., \& PATIL, G. R. (2009). Prediction of sensory quality of UHT milk-a comparison of kinetic and neural network approaches. Journal of Food Engineering, 92(2), 146-151.

SOURAKI, B. A.; GHAVAMI, M.; TONDRO, H. Mass transfer during osmotic dehydration of green bean in salt solution: A polynomial approximation approach. Food and Bioproducts Processing, v. 91, n. 3, p. 257-263, 2013.

SZPARAGA, A., STACHNIK, M., CZERWIŃSKA, E., KOCIRA, S., DYMKOWSKA-MALESA, M., \& JAKUBOWSKI, M. (2019). Multi-objective optimization based on the utopian point method applied to a case study of osmotic dehydration of plums and its storage. Journal of food engineering, 245, 104-111.

TADINI, C. C.; NICOLETTI, V. R.; DE ALMEIDA, M. A. J.; PESSOA, F, P. A Operações Unitárias Na Indústria De Alimentos. RIO DE JANEIRO: LTCLIVROS TÉCNICOS E CIENTÍFICOS, 2016. 484 P.

VIEIRA, S. Estatística para a qualidade. Rio de Janeiro: Elsevier, 2014.

YANÉZ, P.; BALSECA, D.; RIVADENEIRA L.; LARENAS, C. Características morfológicas y de concentración de Capsaicina en cinco especies nativas del genero Capsicum cultivadas en ecuador. La granja: Revista de Ciencias de la Vida. 2015; 22:12-32. 